\title{
Polyoptimisation of the refill friction stir spot welding parameters applied in joining 7075-T6 Alclad aluminium alloy sheets used in aircraft components
}

\author{
Rafał Kluz $^{1}$ (D) $\cdot$ Andrzej Kubit $^{1}$ (D) $\cdot$ Tomasz Trzepiecinski $^{2}$ (D) $\cdot$ Koen Faes $^{3}$
}

Received: 27 February 2019 / Accepted: 8 April 2019 / Published online: 4 May 2019

(C) The Author(s) 2019

\begin{abstract}
In the aerospace industry, the refill friction stir spot welding (RFSSW) method is increasingly used to join thin sheets, especially those made of 2xxx and 7xxx series aluminium alloys. This paper presents the results of spot welding lap joints of 7075-T6 aluminium alloy sheets. The load capacity of joints was determined by tensile/shear tests using a universal testing machine. The effect of tool plunge depth, tool rotational speed and duration of welding on joint load capacity and failure mode was investigated. The polyoptimisation of the values of welding process parameters was carried out to ensure the highest load capacity of the joint at a minimum variance of the results obtained. The selection of the optimal parameters of the RFSSW process was carried out using an adequate mathematical model obtained on the basis of Weierstrass' theorem. It was found that tool rotational speed had the greatest impact on the load capacity of the joints. It was possible to increase the load capacity of the joint by increasing the duration of welding but only to a limited extent. The selection of optimal welding parameters requires a compromise solution, i.e. the selection of a tool rotational speed that ensured adequate plasticisation of the material with a welding duration that ensured that an appropriate joint microstructure was obtained and assured the required load capacity of the joint. The methodology of mathematical modelling of polyoptimisation presented can be useful in optimising similar joining processes.
\end{abstract}

Keywords Aluminium alloy $\cdot$ Polyoptimisation $\cdot$ Friction stir spot welding $\cdot$ Welding parameters

\section{Introduction}

Aluminium alloys are an intensively investigated and widely used group of materials in the aircraft industry due to their high strength and low density. The $2 \mathrm{xxx}$ and $7 \mathrm{xxx}$ series aluminium alloys are commonly used to make up aircraft skins, cowls and other aircraft structures. The basic criterion governing the use of aluminium alloys for

Tomasz Trzepiecinski

tomtrz@prz.edu.pl

1 Department of Manufacturing and Production Engineering, Rzeszow University of Technology, 8 Powst. Warszawy Ave., 35-959 Rzeszów, Poland

2 Department of Materials Forming and Processing, Rzeszow University of Technology, 8 Powst. Warszawy Ave., 35-959 Rzeszów, Poland

3 Belgian Welding Institute, Technologiepark-Zwijnaarde 935, 9052 Ghent, Belgium aircraft parts is the possibility of combining individual elements to ensure the greatest possible strength of the joint [1-3]. The attractiveness of aluminium is that it is a lightweight metal and it is one of the most easily fabricated of the high-performance materials. Key features of aircraft structures are the lowest possible weight and a sufficiently low manufacturing cost [4].

The aluminium alloys used in the aircraft industry are mainly joined by bolting, riveting and bonding. Resistance spot welding (RSW) is a common method for the joining of thin-walled steel structures because of its advantages such as low-cost, reliability, high speed and ease of operation and automation. The RSW process typically involves placing two or more overlapping metal sheets between two electrodes and then applying pressure onto the electrodes in order to clamp the workpieces together $[5,6]$. Then, electrical current is supplied to the sheets to be joined via the two electrodes for a specific period of time. This results in heat generation at the material and consequently a molten nugget is formed [5]. RSW of aluminium alloys is 
difficult due to low bulk resistance and high electrical and thermal conductivity. It requires pressure welding machines with high welding currents. The presence of an oxide layer on the surface of aluminium alloys, which is characterised by high contact resistance, causes rapid degradation of the electrode tip [7]. Another problem of RSW is the warpage deformation of the asymmetric sheet structures which results from the changed residual plastic strain due to thermal deformations $[8,9]$.

The friction stir spot welding (FSSW) technique has been widely studied by many authors. Descriptions of the method, including the relations between the process parameters and joint strength, were provided by, for example, Cao et al. [10], Chen [11] and Kubit et al. [12]. Refill friction stir spot welding (RFSSW) is a modern modification of the FSSW technique which has been extensively investigated over recent years. RFSSW is a solid-state joining technology which connects two similar or dissimilar materials together with minimal heat input or distortion.

The effect of the RFSSW process parameters on the joint microstructure and the load capacity of the joint has become a focus of the investigations of Shen et al. [13] who found that the overlap shear strength increases with increase in weld time and plunge depth due to increasing nugget diameter. Shen et al. [14] found that the void in the RFSSW weld played an important role in joint strength. Furthermore, it was also observed that the main feature affecting the mechanical properties of the joint is the Alclad between the upper and lower sheets. Oberembdt et al. [15] concluded that the most effective variable for controlling the joint strength was plunge depth. Tier et al. [16] studied the effect of tool rotational speed, plunge depth and welding time on the microstructure and shear strength of aluminium joints. It was found that the most significant variables influencing the mechanical performance of welds are tool rotational speed and plunge depth. In contrast volumetric defects have little influence on the shear strength of the joints. Verastegui et al. [17] applied the Taguchi statistical method to find out the set of parameters indicated to produce a joint with higher strength. He found that the galvanised layers of sheet to be joined do not cause any substantial effect on joint strength.

The state of knowledge concerning the phenomena occurring during the RFSSW process means that it is not fully understood in a satisfactory way, which results in difficulties in the selection of the optimal welding process for joining specific aluminium alloys [18-20]. The welding of the Alclad covered aluminium alloy sheets commonly used in the aircraft industry, which are the test material in this paper, is difficult to conduct. The Alclad protects metal sheets against corrosion. It will, however, diminish the mechanical properties of the joints because it cannot stir together with the base materials. So, Alclad within the weld nugget causes heterogeneity in the structure of the weld. Alclad also makes the process of recrystallisation difficult. The welding of Alclad sheets requires special attention and precise welding procedures. Many authors used the trial and error method to select optimal process parameters, which makes it difficult to generalise the relationship between process parameters and joint quality. In addition, the Alclad sheets required for optimal joining conditions have different parameters than is the case with plates without the plating layer. The difference is largely due to the fact that Alclad, i.e. high-purity aluminium (99.9\%), is characterised by a significantly higher value of thermal conductivity than the 7075-T6 aluminium alloy. Therefore, the heat generated in the welding process is non-uniformly distributed in the sheets to be joined due to the rapid dissipation of heat through the Alclad layer.

Methods commonly used to plan experiments, such as the Taguchi method, allow one to limit the research plan and determine the maximum value of the regression function, usually taking into account only one criterion, the load capacity of the joint. The results of previous RFSSW welding tests [12, 21] indicate that the parameters ensuring the maximum load capacity of the joint, however, result in a large scatter of results. Therefore, the aim of the investigations was to develop the methodology to determine optimal values of the welding parameters ensuring the maximum load capacity of the joint with the smallest possible variation in the results. Multicriteria optimisation was used to achieve this goal. The method presented required experimental determination of the influence of RFSSW parameters on the load-bearing capacity of single lap joints of the 7075-T6 Alclad aluminium alloy sheets commonly used in aircraft applications.

\section{Experimental procedure}

\subsection{Material}

The single-lap joints were made in 7075-T6 Alclad aluminium alloy sheets. The chemical composition of the sheet material is listed in Table 1. The 7075-T6 aluminium alloy has high mechanical strength - comparable to structural steels, and very high fatigue strength.

Table 1 Chemical composition of 7075-T6 Alclad aluminium alloy (wt.\%)

\begin{tabular}{lllllllll}
\hline $\mathrm{Si}$ & $\mathrm{Fe}$ & $\mathrm{Cu}$ & $\mathrm{Mn}$ & $\mathrm{Mg}$ & $\mathrm{Cr}$ & $\mathrm{Zn}$ & $\mathrm{Ti}$ & Other impurities single total \\
\hline 0.40 & 0.50 & $1.2 \sim 2.0$ & 0.30 & $2.1 \sim 2.9$ & $0.18 \sim 0.28$ & $5.1 \sim 6.1$ & 0.30 & 0.050 .15 \\
\hline
\end{tabular}




\subsection{Welding procedure}

The RFSSW process involves a three-piece non-consumable rotational tool with independently controlled sleeve and pin components, which rotate simultaneously at a constant speed with the sleeve only penetrating into the upper sheet. The process of welding sheets using the RFSSW method consists of three main phases [22, 23]. In the first phase, the pin and sleeve are positioned on the surface of the upper sheet. A clamping ring compresses the sheets to be joined (Fig. 1a), protecting the materials from uncontrolled displacement. Then, the sleeve and pin are accelerated to their nominal rotational speed. In the second phase, the sleeve and pin move downward and upward, respectively, and therefore the plasticised material displaced by the sleeve is squeezed into the cylindrical cavity created by the upward movement of the pin (Fig. 1b). After reaching a predetermined plunge depth, the direction of movement of both the sleeves and the pin begins to reverse and the plasticised material in the cylindrical cavity is squeezed back by the pin (Fig. 1c). Finally, the pin and sleeve are positioned at the initial position and the tool is removed. The tests of the sheet welding process were carried out on a friction welding machine with RPS 100 VA11 manufactured by Hams \& Wende GmbH \& Co KG (Fig. 2). The diameters of the pin and the sleeve were $5.2 \mathrm{~mm}$ and $9 \mathrm{~mm}$, respectively.

7075-T6 Alclad aluminium sheets were refill friction stir spot weldedintheoverlapping configurationshowninFig.3.Next,specimens of $120 \mathrm{~mm} \times 30 \mathrm{~mm}$ were cut from the welded sheets using a precisioncutoffmachineundercooling conditions. Thethicknessof thelowersheetwas $0.8 \mathrm{~mm}$, andthethicknessoftheuppersheet, where the welding tool operates, was $1.6 \mathrm{~mm}$. This configuration (Fig. 3) correspondstothejoiningofastringerwiththeskinintheactualaircraft structure[12,21].

The range of the changes of the welding process parameters was determined based on previous research by Kubit et al. [12,
21]. The range specified corresponded to the values of process parameters which significantly affect the load capacity of the RFSSW joint. Welding was conducted using the following values of parameters:

- $\quad$ Tool rotational speed $n(2000,2400,2800 \mathrm{rpm})$,

- Tool plunge depth $g(1.3,1.5,1.7,1.9 \mathrm{~mm})$,

- Duration of welding $t(1.5,2.5,3.5 \mathrm{~s})$.

The tests carried out (by Kubit et al. [12, 21]) showed that the highest load capacity of the welds in the joints being assessed can be obtained using a tool plunge depth of about $93 \%$ of the thickness of the upper sheet $(1.5 \mathrm{~mm})$. During the fabrication of these welds, both the pin and the sleeve did not penetrate the thinner lower sheet. Because previous tests were carried out with a very limited range of variation of the other welding parameters, it was decided to perform tests for a wider range of the welding parameters, i.e. at plunge depths of $1.3 \mathrm{~mm}$ and $1.5 \mathrm{~mm}$ ensuring no penetration of the lower sheet and at depths of $1.7 \mathrm{~mm}$ and $1.9 \mathrm{~mm}$ allowing penetration of the lower sheet material, in the research presented in this paper. Welding tests were carried out for all combinations of the above parameters whose values changed over a wide range. For the purposes of the optimisation analysis, the following welding parameters were adopted: $x_{1}$, tool rotational speed; $x_{2}$, tool plunge depth; and $x_{3}$, duration of welding.

\subsection{Tensile/shear testing}

Investigation of the load capacity of the joint by tensile/ shear tests was carried out using a ZWICK Roell Z-100 universal testing machine with a constant crosshead (a)

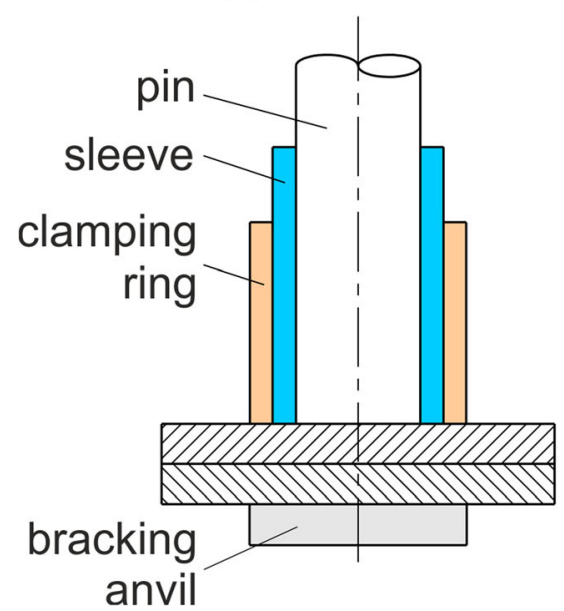

(b)
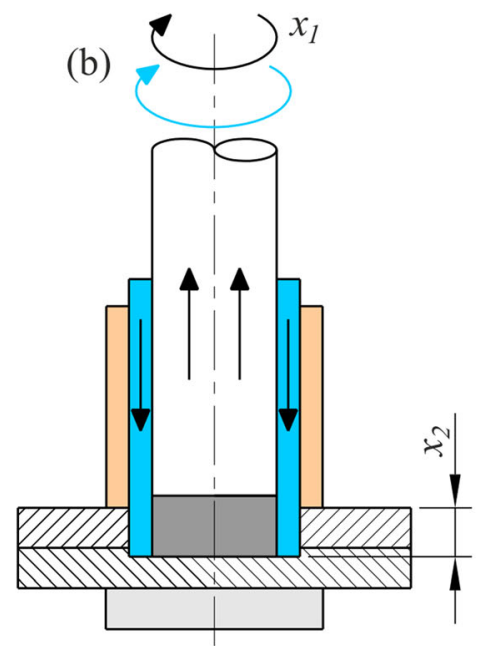

(c)

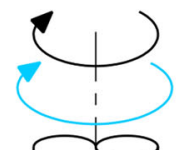

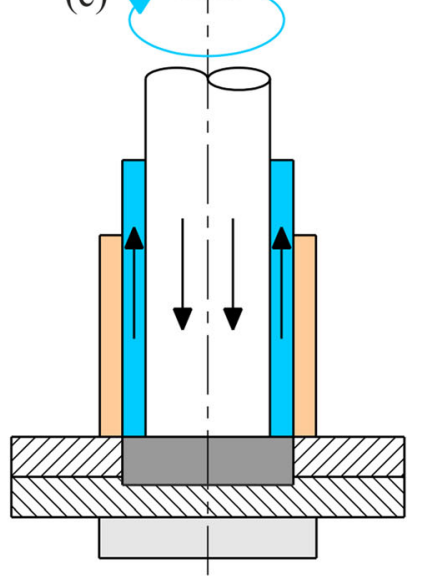

Fig. 1 Stages of the RFSSW process: (a) contact, (b) plunge and (c) refill 
Fig. 2 Work table of RPS 100 VA11 refill friction stir spot friction welding system

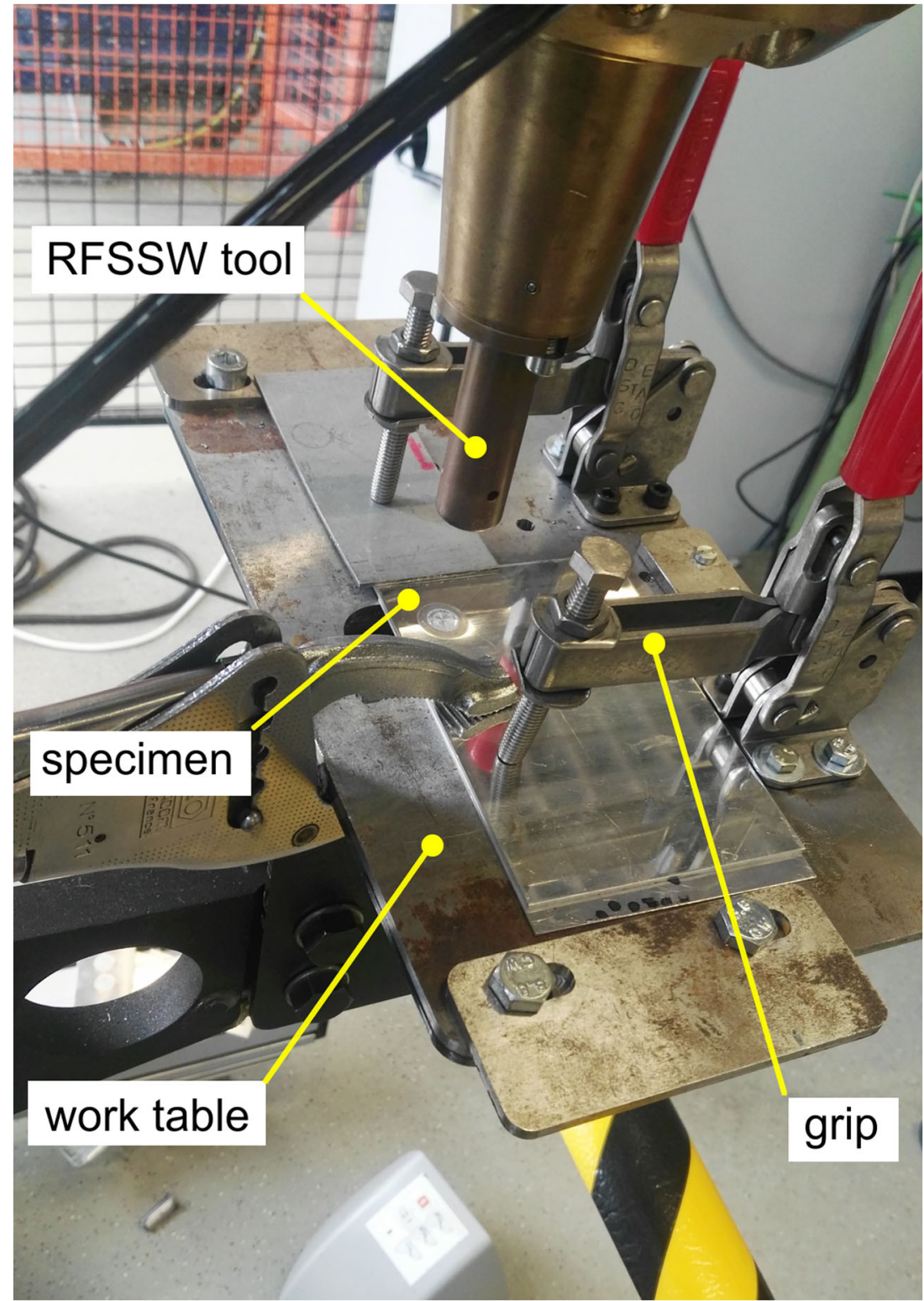

speed of $5 \mathrm{~mm} / \mathrm{min}$ at ambient temperature. Conducting a tensile/shear test for the samples shown in Fig. 3 is associated with the occurrence of significant normal stresses, which result in the joint being subjected to shearing and peeling. In real-life conditions, the joining of structural elements is carried using many joints. The stiffness of such a structure is much greater than the stiffness of a single specimen, so that the effect of the normal component of force generated during the operation of the joint is very limited and its load capacity is usually not affected significantly by normal stresses.

\section{Results and discussion}

\subsection{Effect of plunge depth}

The first stage of the research is focused on the analysis of the effect of tool plunge depth $x_{2}$ on the load capacity of the joint. For this purpose, the welds were fabricated at a tool plunge depth equal to $1.3,1.5,1.7$, and $1.9 \mathrm{~mm}$, with three different tool rotational speeds 2000, 2400, and $2800 \mathrm{rpm}$. The load capacity of the joints obtained ranged from $5510 \mathrm{~N}$ to $8000 \mathrm{~N}$ (Fig. 4a). 

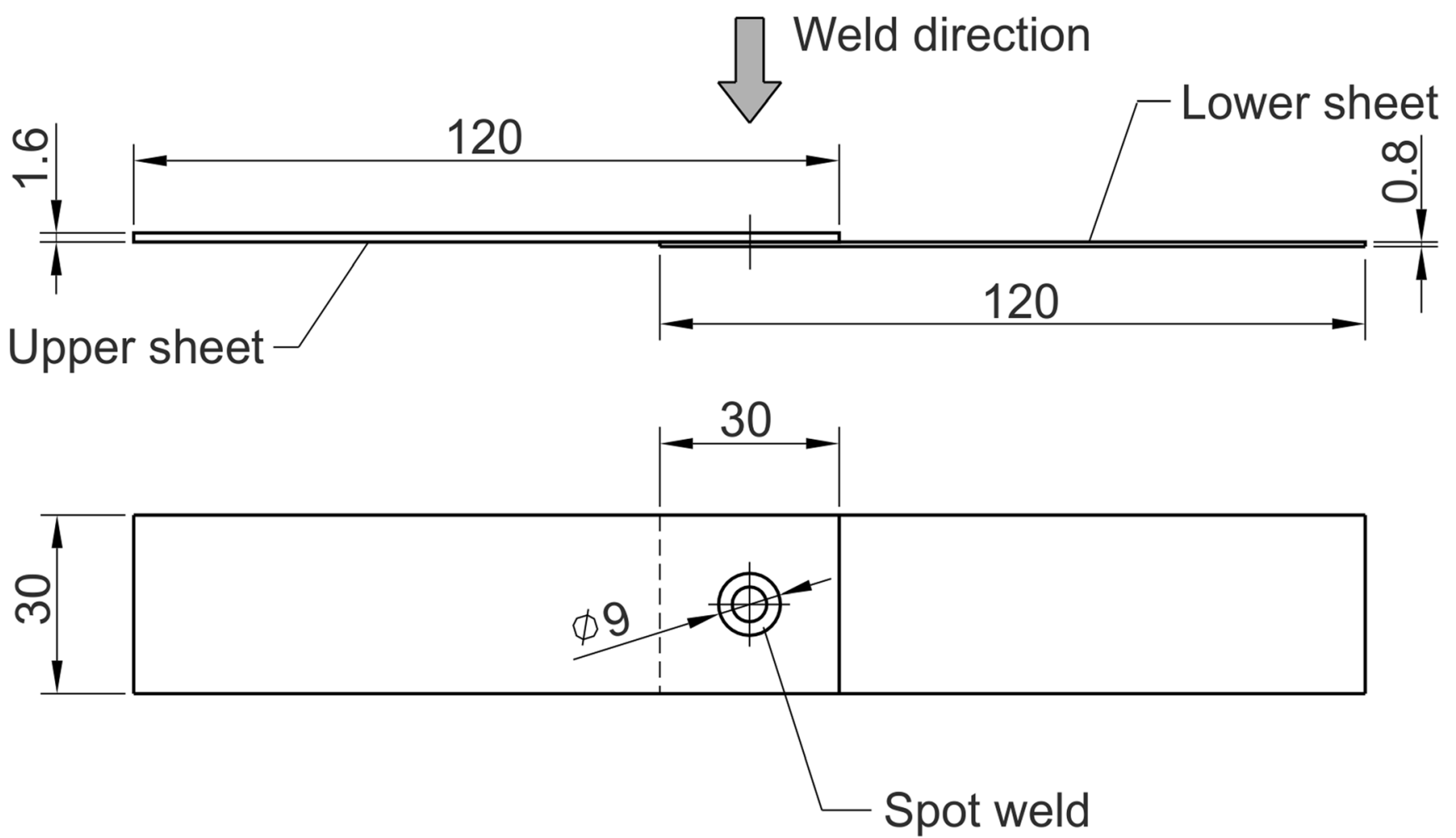

Fig. 3 Geometry and dimensions of the specimens for tensile/shear testing

The curves assigned to the appropriate tool rotational speeds have the same trends. Regardless of the assumed tool rotational speed, the highest load capacity of the joint is observed for a tool plunge depth of $x_{2}=$ $1.5 \mathrm{~mm}$. After exceeding this value, all characteristics show a trend to a lowering of the strength of the joint as the tool plunge depth increases. In the case of a curve corresponding to a rotational speed of $2800 \mathrm{rpm}$, an initial significant increase in weld strength was achieved, reaching a maximum value of $8010 \mathrm{~N}$ for a tool plunge depth of $1.5 \mathrm{~mm}$, after which the trend reverses as the tool plunge depth increases and the joint strength decreases. The largest decrease in load capacity from 8010 to $6265 \mathrm{~N}(-21.78 \%)$ is observed with the highest tool rotational speed. The decrease in the load capacity of the joint with increasing tool plunge depth is due to the weakening of the lower part of the weld by the sleeve worked in the second stage of welding (Fig. 1b).

In aircraft construction, the standard deviation of the results obtained is also an important parameter in addition to the load capacity of the joint itself. A smaller value of the deviation is related to a greater repeatability of the process, which is reflected in the reliability of the construction. The evaluation of the repeatability (stability) of the process was carried out using the
Hartley test. In order to verify the hypothesis about the repeatability of the variance, the $F_{\max }$ test statistic was determined:

$F_{\text {max }}=\frac{s^{2}(y)_{i \max }}{s^{2}(y)_{i \max }}$

where $s^{2}(y)_{i \text { max }}$ and $s^{2}(y)_{i \text { min }}$ are the maximum and minimum values from the set of all variances, respectively.

The critical values of the Hartley test $f_{\max (\mathrm{a}, \mathrm{k}, \mathrm{v})}$ for the number of degrees of freedom $k=m=36, v=r-1=$ $5-1=4$ and the significance level $\alpha=0.05$ were derived from statistical tables and compared with the calculated value of $F_{\max }$. The analysis of the test showed that the results obtained at different values of the welding process parameters do not have the same variance $\left(F_{\max }>\right.$ $f_{\max (\mathrm{a}, \mathrm{k}, \mathrm{v})}$ ).

Analysis of the test results also indicated some dependence regarding the values of variance and standard deviation. The standard deviation of the test results was determined on the basis of 5 -element samples. Apart from the assumed tool rotational speed, the highest standard deviation value was observed for a tool plunge depth of $1.5 \mathrm{~mm}$, i.e. at the plunge depth ensuring the highest load capacity of the joint (Fig. 4b). 
Fig. 4 The effect of tool plunge depth on the load capacity of the joint (a) and standard deviation of the test results (b) with a duration of welding $x_{3}=1.5 \mathrm{~s}$ (a)

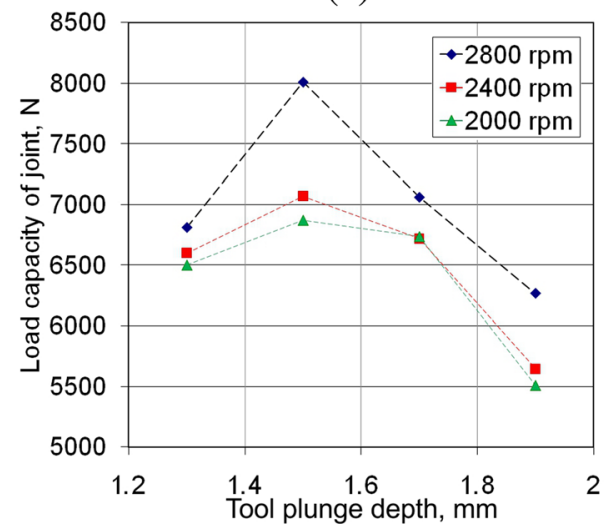

(b)

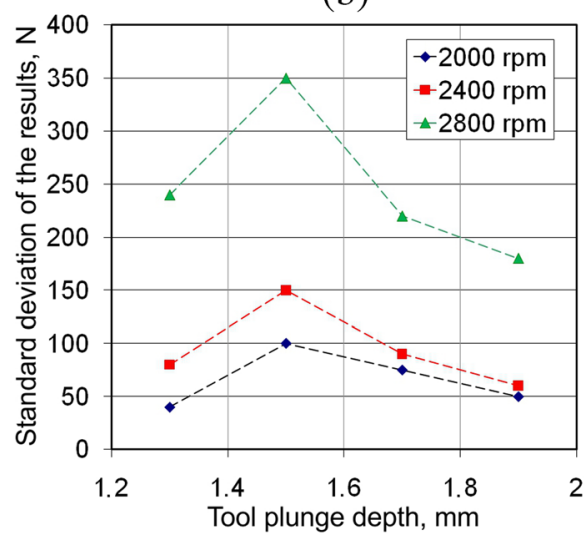

\subsection{Effect of tool rotational speed}

In the next part of the research, the focus was put on determining the influence of tool rotational speed and the duration of welding on the load capacity of joints. The test results obtained for tool plunge depth $x_{2}=1.5 \mathrm{~mm}$ are shown in Fig. 5a. For the durations of welding $x_{3}=1.5 \mathrm{~s}$ and $2.5 \mathrm{~s}$, an increase of tool rotational speed causes an increase in the load capacity of the joint. For the duration $x_{3}=1.5 \mathrm{~s}$, an increase in the tool rotational speed from 2000 to $2800 \mathrm{rpm}$ results in an increase in load capacity by $17.9 \%$ (from 6870 to $8100 \mathrm{~N}$ ), while for the welding time $x_{3}=2.5 \mathrm{~s}$, it does this by $11.5 \%$.

An increase in tool rotational speed causes an increase in weld temperature leading to better plasticisation of the material and an increasing strength of the joint. At the same time, an increase in the susceptibility of the tool surface to sticking to aluminium alloy sheet material was noted. During the tests with the highest speeds, the plasticised material stuck to the working elements of the tool, resulting in a necessity for frequent cleaning, thus increasing the labour requirements of the welding process. The adhering material also made it difficult for the tool to obtain the assumed plunge depth, as a result of which a much larger dispersion of the test results was observed than in the case of joints fabricated at a lower tool rotational speed (Fig. 5b).

In the case of welds performed for a welding duration $x_{3}=$ $3.5 \mathrm{~s}$, it can be noted that an increase in tool rotational speed from 2000 to $2400 \mathrm{rpm}$ enabled the load capacity of the joint to increase by $8.3 \%$ (from 7000 to $7587 \mathrm{~N}$ ). Further increases in tool rotational speed caused a reduction in load capacity of the joint by $7.25 \%$, which was a result of an excessive temperature rise during joint formation. As a result, tearing of the weakened fragment of the lower sheet is observed, which will be discussed in the next section of this paper.

\subsection{Failure modes}

During the tensile/shear tests of joints, three types of failure mode were observed: nugget debonding or alternatively shear type fracture, plug shear type fracture on the lower sheet, and tear plug fracture with a tear on the lower sheet. Figure 6 shows the main types of defects corresponding to specific failure modes. In the case of the use of a rotational speed of $2800 \mathrm{rpm}$ with a welding duration in the interval
Fig. 5 Effect of tool rotational speed on the load capacity of the joint (a) and standard deviation of the test results (b) for a tool plunge depth $x_{2}=1.5 \mathrm{~mm}$ (a)

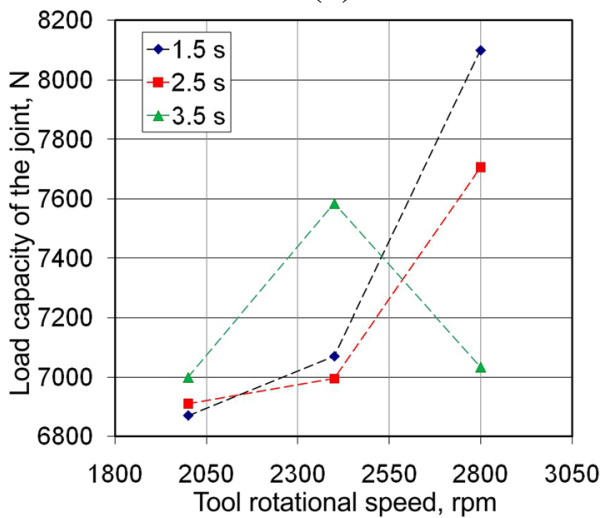

(b)

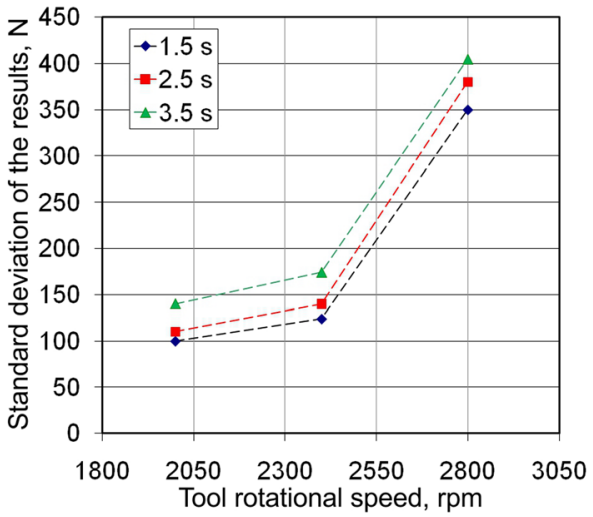


(a)

(b)

(c)

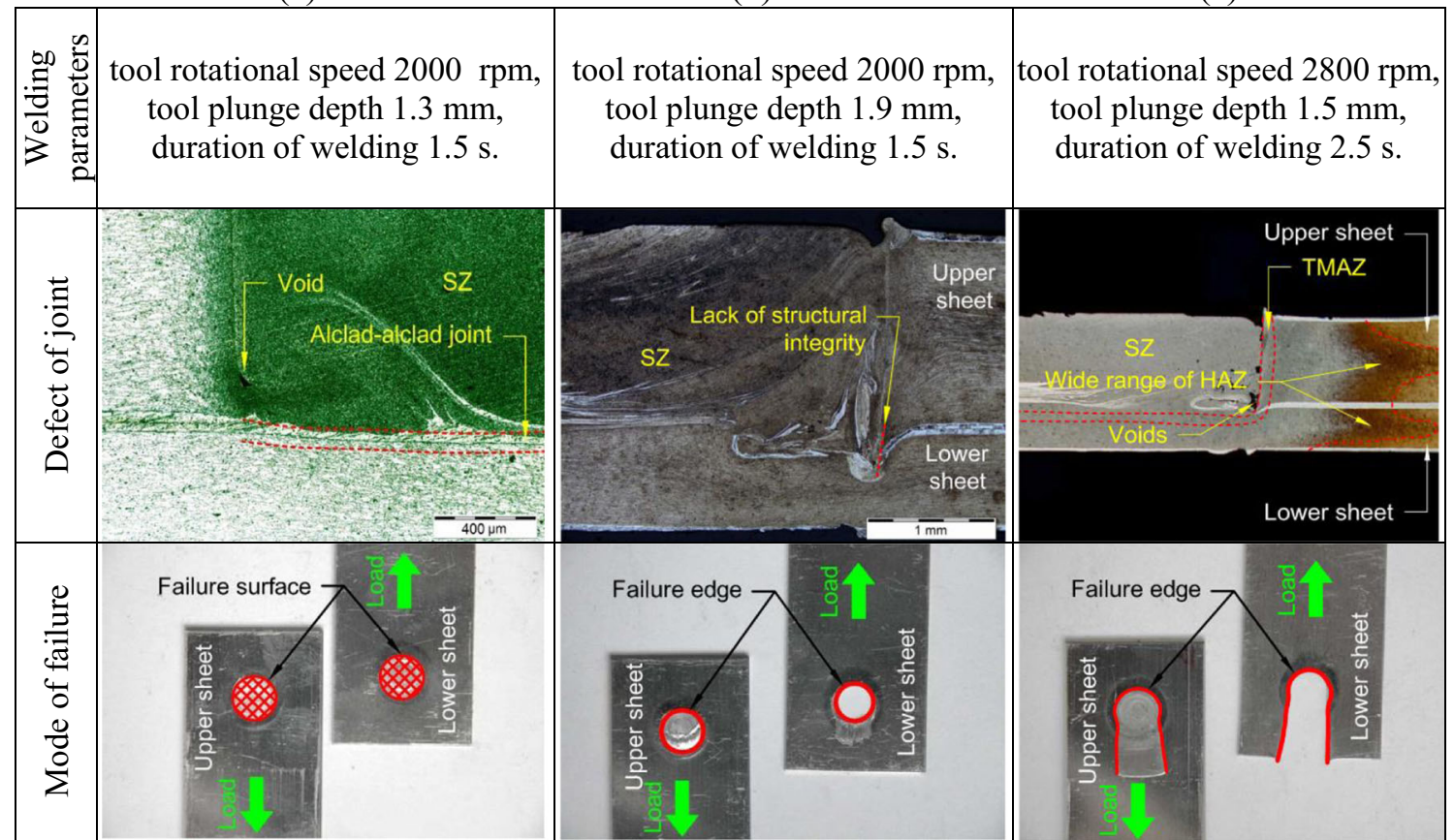

Fig. 6 Cross-sectional view of a RFSSW specimen (top view) and the corresponding failure modes (bottom view): (a) nugget debonding, (b) plug type fracture on the lower sheet, (c) tear plug fracture with tear on the lower sheet

$<1.5,2.5\rangle$, a type of specimen failure was observed characterised by separation (tearing) of the lower sheet (Fig. 6c). The weld formed by the stirring of the base material (BM) is composed of several parts (Fig. 7): the weld core, a structural notch resulting from sleeve operation and three metallurgical zones: the stir zone (SZ), the thermomechanically affected zone (TMAZ) and the heat-affected zone (HAZ). The weld nugget has a fine-grained structure with better mechanical properties than the base material, clearly demonstrating the occurrence of a recrystallisation process caused by high temperature and high pressure. In consequence, a plug tear fracture mode can be seen.

The plug type fracture mode (Fig. 6b), characterised by the pulling out of the weld nugget on the lower sheet, was observed in the case of low tool rotational speed (2000 rpm), short welding times $(1.5 \mathrm{~s})$, and larger tool plunge depths $(1.7 \mathrm{~mm}, 1.9 \mathrm{~mm})$. The joints made with the given parameters were characterised by the lowest load capacity due to the structural notch on the perimeter of the weld. The presence of a clear structural notch indicates that the sleeve has plunged too quickly into the base material, which instead of plasticising the material causes its partial cutting. At the same time, the rise of temperature in the later stage of the RFSSW process leads to recrystallisation and a partial reconstruction of the material. The plug fracture mode is associated with a lack of mixing between the boundary between the TMAZ and $\mathrm{SZ}$ and the preferred bond between the upper and lower sheets, respectively. This was also noted by Shen et al. [14].
A reduction in tool plunge depth $(1.3 \mathrm{~mm}, 1.5 \mathrm{~mm})$ leads to nugget debonding characterised by crack propagation along the original lap interface (Fig. 6a) after being initiated from the hook tip. With sufficient stirring of the Alclad layers of the upper and lower sheets with the BM, then a shear type fracture mode is observed instead. In this case, the fracture propagates through the nugget along the original lap interface. This shear fracture mode is the dominant fracture mode under crosstension loadings [14].

The RFSSW weld face is characterised by great roughness resulting from the operation of the tool whose surface is

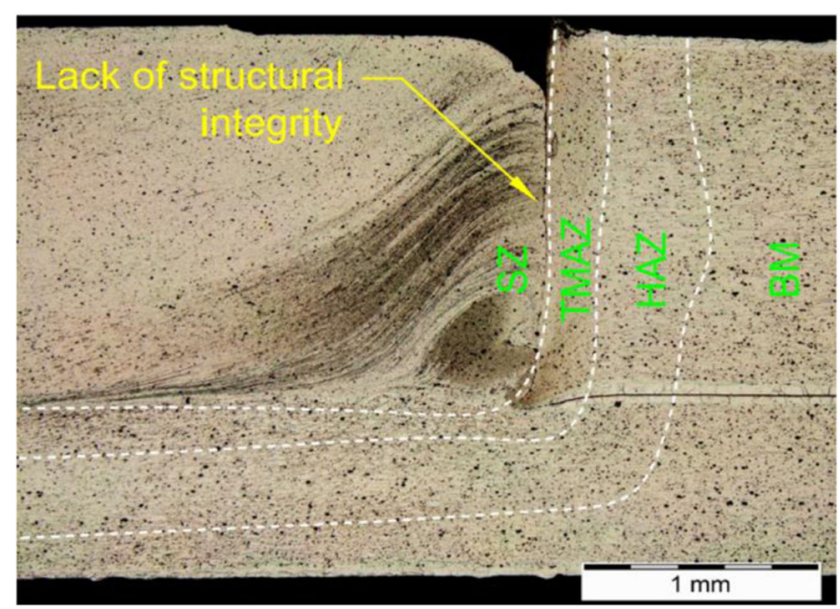

Fig. 7 Cross-sectional view of a weld fabricated at a speed of $x_{1}=$ $2000 \mathrm{rpm}$, tool plunge depth of $x_{2}=1.5 \mathrm{~mm}$ and duration of welding $x_{3}=1.2 \mathrm{~s}$ 


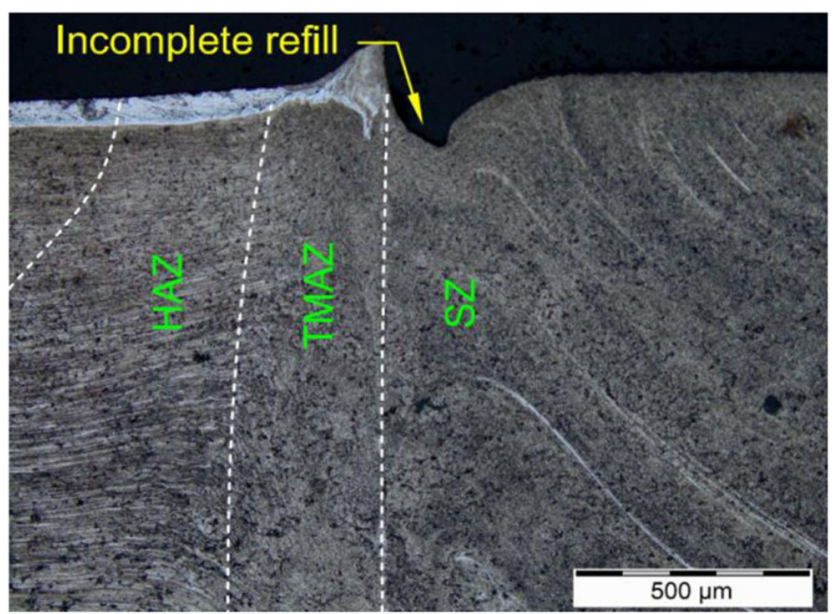

Fig. 8 Cross section of the edge of a weld fabricated with the parameters $x_{1}=2800 \mathrm{rpm}, x_{2}=1.50 \mathrm{~mm}, x_{3}=1.5 \mathrm{~s}$

heterogeneous due to adhesion of the plasticised material. Incomplete refill is visible on the surface of the upper sheet (Fig. 8). There is a heat-affected zone from the structural notch in the direction of the sheet metal material (Figs. 7 and 8). The width of this zone depends on the duration of welding. An increase in the duration of welding clearly leads to an increase in the temperature within the weld and the diffusion of heat in each direction. This is evidenced by an enlarged HAZ on the edges of the weld and a more complete rebuilding of the material in the area of sleeve penetration. Heat diffusion also takes place in the area of the bottom of the weld leading to adhesive joining of the sheets to be joined.

\section{Mathematical modelling}

The selection of the optimal parameters of the welding process requires the determination of an adequate mathematical model in the form of the regression function $W(x)$. Regression analysis was carried out using the least squares method with the following criterion assessing the quality of the approximation:

$R=\min \sum_{i=0}^{N}\left[f\left(x_{i}\right)-W\left(x_{i}\right)\right]^{2}$

where the value of the function $R$ is a certain measure of the deviation of the approximation function $W(x)$ from the approximated function $f(x), i=1, \ldots$ and $N$, number of experiments.

During the approximation, the most frequently selected basic functions are monomials according to Weierstrass' theorem. This theorem defines that for every function $f(x)$ specified and continuous on a closed and limited interval $[\mathrm{a}, \mathrm{b}]$ there exists a polynomial $W=b_{0}+b_{1} x_{1}+b_{\mathrm{m}} x^{\mathrm{m}}$, that approximates monotonously the function $f(x)$ on the interval $[\mathrm{a}, \mathrm{b}]$.
During the analysis, however, it was not possible to obtain such a polynomial with a rational $m$ level which could be considered adequate. Therefore, the $m$-degree algebraic polynomial was adopted for the definition of the interactions between the RFSSW process parameters:

$$
\begin{aligned}
& W(x)= b_{0}+\sum_{i=1}^{S} b_{i}^{(1)} x_{i}+\sum_{\substack{i, j=1 \\
i<j}}^{S} b_{i j}^{(1)} x_{i} x_{i} \\
&+ \sum_{\substack{i, j, \ldots l, n=1 \\
i<j, \ldots, l<n}}^{S} b_{i j \ldots l n}^{(1)} x_{i} x_{j} \ldots x_{l} x_{n} \\
&+\sum_{\substack{i, j=1 \\
i \neq j}}^{S} b_{i j}^{(2)} x_{i}^{2} x_{j}+\sum_{i=1}^{S} b_{i i \ldots m}^{(m)} x_{i}^{m} \\
&
\end{aligned}
$$

In Eq. (3), there exists $L$-number of unknown coefficients $b_{0}, b_{i}^{(1)}, b_{i j}^{(1)}, b_{i j \ldots l n}^{(1)}, b_{i j}^{(2)}, b_{i i . \ldots m}^{(m)}$ while $i, j, \ldots, n=1, \ldots, S$ variables of a polynomial (3).

The assessment of the significance of the coefficients in the regression equation was performed by comparing their values with the critical value determined on the basis of the formula:

$b_{k r}=t_{(\alpha, f)} \sqrt{\frac{S^{2}(y)}{N r}}$

Table 2 Values of coefficients in the regression equations $W_{F}(x)$ and $W_{\sigma}(x)$

\begin{tabular}{lll}
\hline Coefficient & $W_{F}(x)$ & $W_{\sigma}(x)(*)$ \\
\hline$b_{0}$ & $10,878.1$ & -8585.36 \\
$b_{1}^{(1)}$ & -18.751 & -1.0813 \\
$b_{2}^{(1)}$ & 9753.29 & $18,367.7$ \\
$b_{3}^{(1)}$ & -4329.75 & -63.958 \\
$b_{12}^{(1)}$ & 28.626 & 0.1364 \\
$b_{13}^{(1)}$ & 8.878 & 0.0164 \\
$b_{23}^{(1)}$ & -3808.33 & - \\
$b_{12}^{(2)}$ & -0.00426 & - \\
$b_{21}^{(2)}$ & -2.877 & - \\
$b_{13}^{(2)}$ & -0.000194 & - \\
$b_{23}^{(2)}$ & 1187.5 & - \\
$b_{11}^{(2)}$ & -0.0054 & 0.0000838 \\
$b_{22}^{(2)}$ & $-14,944.4$ & $-10,739.6$ \\
$b_{33}^{(2)}$ & -1153.15 & 9.791 \\
$b_{111}^{(3)}$ & $2.3485 \cdot 10^{-6}$ & $6.304 \cdot 10^{-8}$ \\
$b_{222}^{(3)}$ & 1921.3 & 2094.91 \\
$b_{333}^{(3)}$ & 164.087 & - \\
\hline
\end{tabular}

(*) means that the coefficient is statistically insignificant 


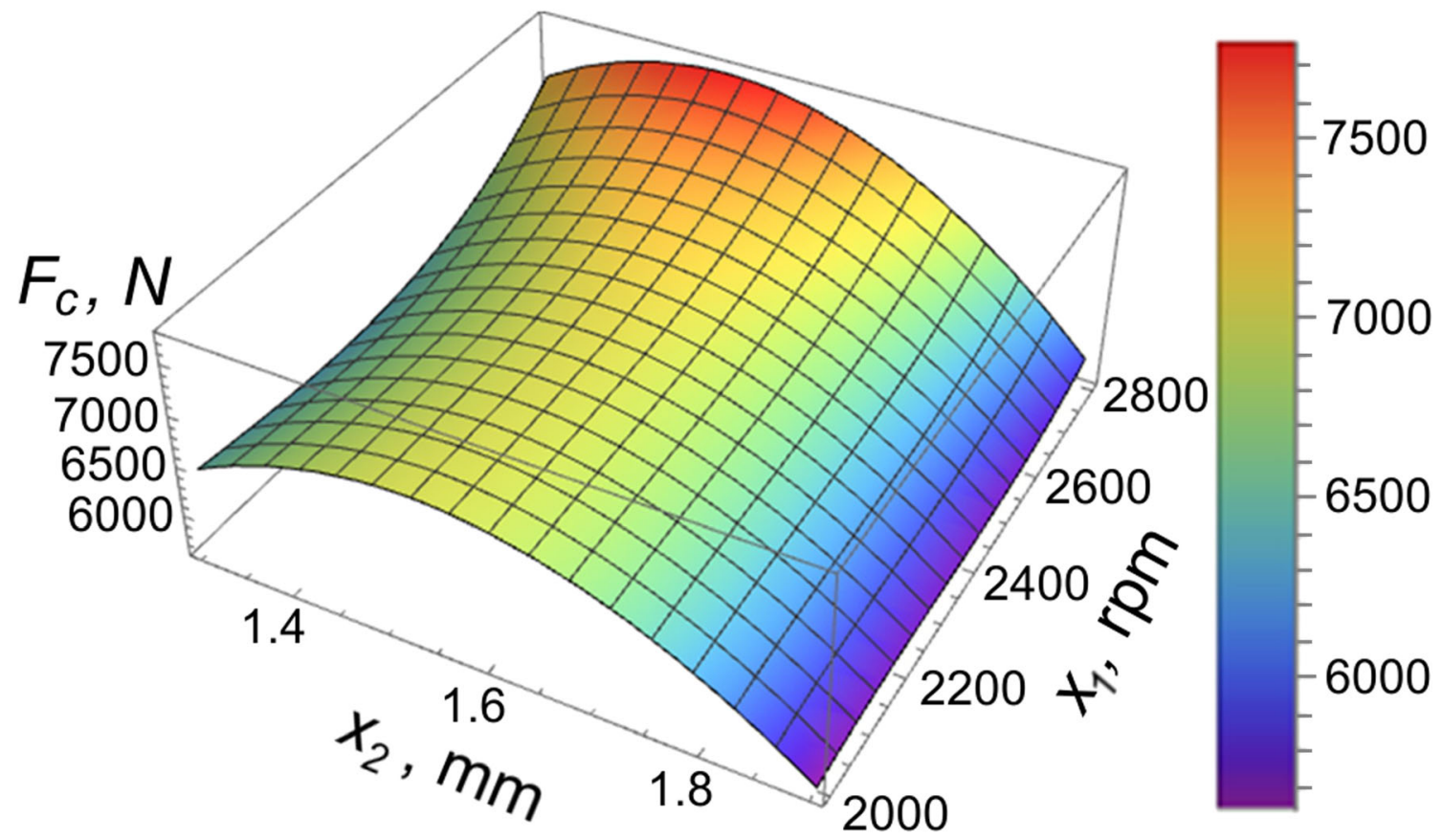

Fig. 9 The influence of tool rotational speed and tool plunge depth on the load capacity of a joint

where: $t_{(\alpha, f)}=t_{k r}$ is the test value of the coefficient $t$ determined based on the basis of the $t$-Student distribution table, $r$ is the number of repetitions.

The Fisher-Senecor test was used to assess the adequacy of the regression equation with the test results. At the first stage of the analysis, the adequacy of the variance was determined, according to the following formula:

$S_{a d}^{2}=\frac{r \sum_{i=1}^{N}\left(\overline{y_{1}}-\overline{y_{1}}\right)^{2}}{N-k-1}$

where $\overline{y_{i}}$, average value of measurement results in the $i$-th experiment; $\overline{\overline{y_{i}}}$, value calculated from the regression equation for the levels of input and output factors in $i$-th experiment; $k$, a number of terms in the regression equation (without a free term) after rejection of the insignificant terms; $N$, the total number of experiments.

Then the value determined for the test coefficient $F$ :

$F=\frac{S_{a d}^{2}(y)}{S^{2}(y)}$

was compared with the critical value determined from the Fisher-Snedecor distribution table. This allowed an adequate regression equation to be obtained describing the influence of the RFSSW process parameters on the load capacity of joints, with the following form:

$$
\begin{aligned}
W_{F}(x)= & b_{0}+b_{1}^{(1)} x_{1}+b_{2}^{(1)} x_{2}+b_{3}^{(1)} x_{3}+b_{12}^{(1)} x_{1} x_{2} \\
& +b_{13}^{(1)} x_{1} x_{3}+b_{23}^{(1)} x_{2} x_{3}+b_{12}^{(2)} x_{1}^{2} x_{2}+b_{21}^{(2)} x_{2}^{2} x_{1} \\
& +b_{13}^{(2)} x_{1}^{2} x_{3}+b_{23}^{(2)} x_{2}^{2} x_{3}+b_{11}^{(2)} x_{1}^{2}+b_{22}^{(2)} x_{2}^{2} \\
& +b_{33}^{(2)} x_{3}^{2}+b_{111}^{(3)} x_{1}^{3}+b_{222}^{(3)} x_{2}^{3}+b_{333}^{(3)} x_{3}^{3}
\end{aligned}
$$

The values of coefficients for the regression function describing the load capacity of the joint $W_{F}(x)$ and standard deviation of the process $W_{\sigma}(x)$ are given in Table 2.

Figure 9 shows a graph of the regression function for a constant value of duration of welding equal to $x_{3}=1.5 \mathrm{~s}$. The maximum error value of the regression function did not exceed $6.11 \%$, while the mean square error between the experimental and mathematical modelling results was equal to $2.55 \%$. The graph shows a clear increase in the load capacity of the joint with an increase in tool rotational speed and a local maximum of the regression function at a tool plunge depth of $1.5 \mathrm{~mm}$. The shape of the function obtained can explain the large standard deviation values obtained with regard to the load capacity of joints for a tool plunge depth of $x_{2}=1.5 \mathrm{~mm}$ and tool rotational speed $x_{1}=2800 \mathrm{rpm}$. A regression function, after reaching the maximum, rapidly falls both towards the larger and smaller values of tool plunge depth. It is very difficult to set the tool at the appropriate plunge depth due to the high plasticity of the material (the sticking of the sheet material to the tool surface). Even a small error in the tool plunge 


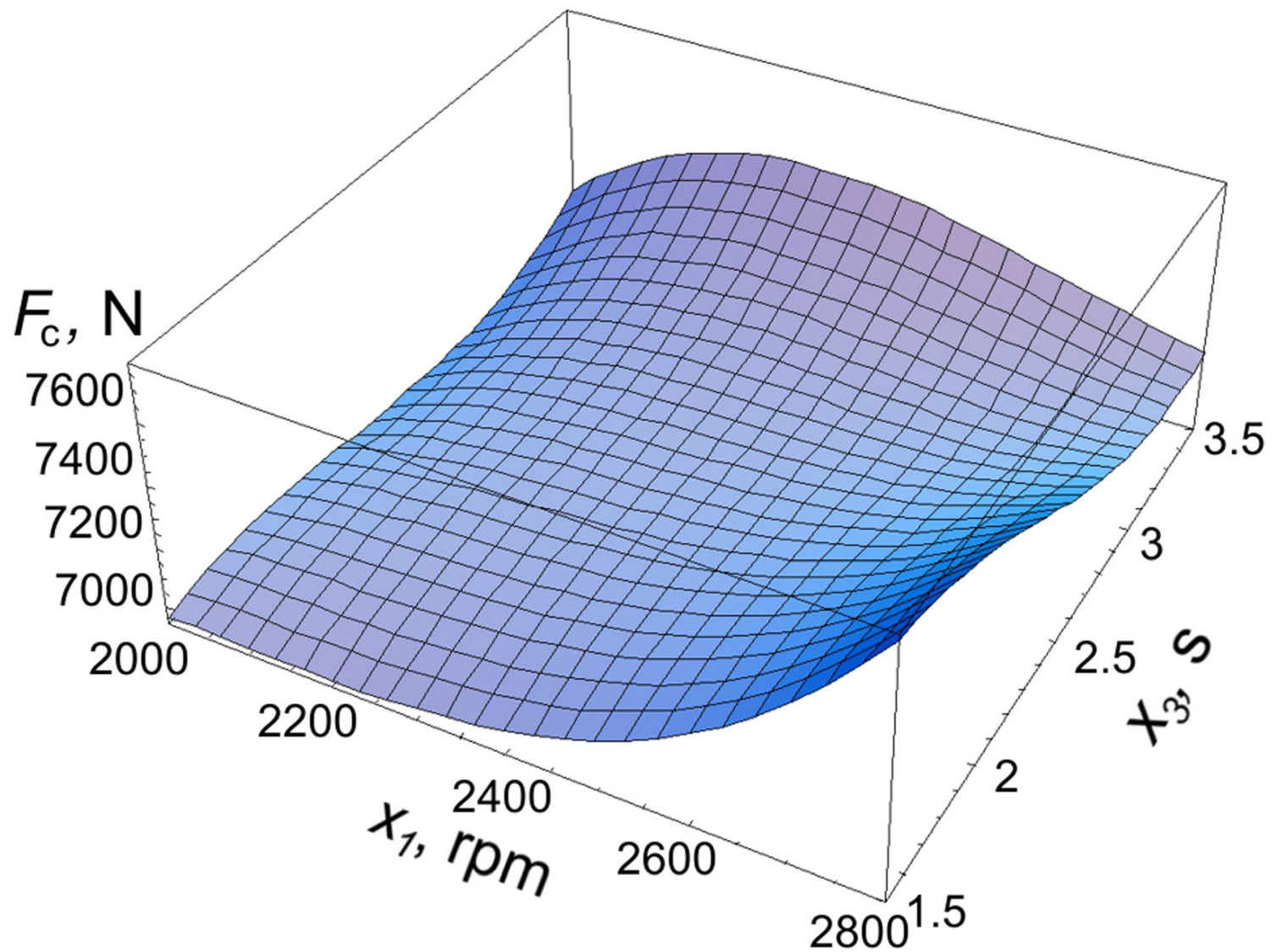

Fig. 10 The effect of tool rotational speed and tool plunge depth on the load capacity of the joint

depth can significantly affect the load capacity of the joint, which is manifested by a large variance of results.

At a tool plunge depth of $x_{2}=1.5 \mathrm{~mm}$ (Fig. 10), an increase in tool rotational speed results in an increase in the load capacity of the joint. This is observed for durations of welding ranging from 1.5 to $2.5 \mathrm{~s}$. A further increase in the duration of welding results in a sudden decrease in the load capacity of the joint.

The regression function describing the variation of process $W_{\sigma}(x)$ that meets the Fisher-Snedecor adequacy criterion has a much simpler form (Table 2). The maximum error of the regression function in this case did not exceed $14.51 \%$, while the mean square error was $14.59 \%$. Figure 11 shows the influence of tool rotational speed and tool plunge depth on the process stability (standard deviation). Analysis of the chart indicates that the increase in tool rotational speed causes an increase in the value of the standard deviation. Therefore, the use of a tool rotational speed of $2800 \mathrm{rpm}$ in order to assure maximum load capacity of the joint may not be justified. In a real structure consisting of a large number of joints, only some will be able to transfer the maximum load, which may contribute to reducing its reliability.
A similar tendency to reduce process stability can be observed by analysing the graph of the influence of the tool rotational speed and the duration of welding on the standard deviation of the load capacity of the joints (Fig. 12). An increase in the duration of welding also leads to a reduction in process stability.

\section{Polyoptimisation of RFSSW process parameters}

In order to replace classic resistance welding by the RFSSW technique, thus ensuring a better quality of welds, it is necessary to select optimal welding parameters. This selection must guarantee not only a high load capacity of the joints produced, but also high process stability, characterised by the lowest possible value of the variance of the results obtained. This requires multi-criteria optimisation of the process and finding a compromise solution that meets the abovementioned mathematical model.

For the writing of the multi-criteria problem, the following designations have been adopted: 


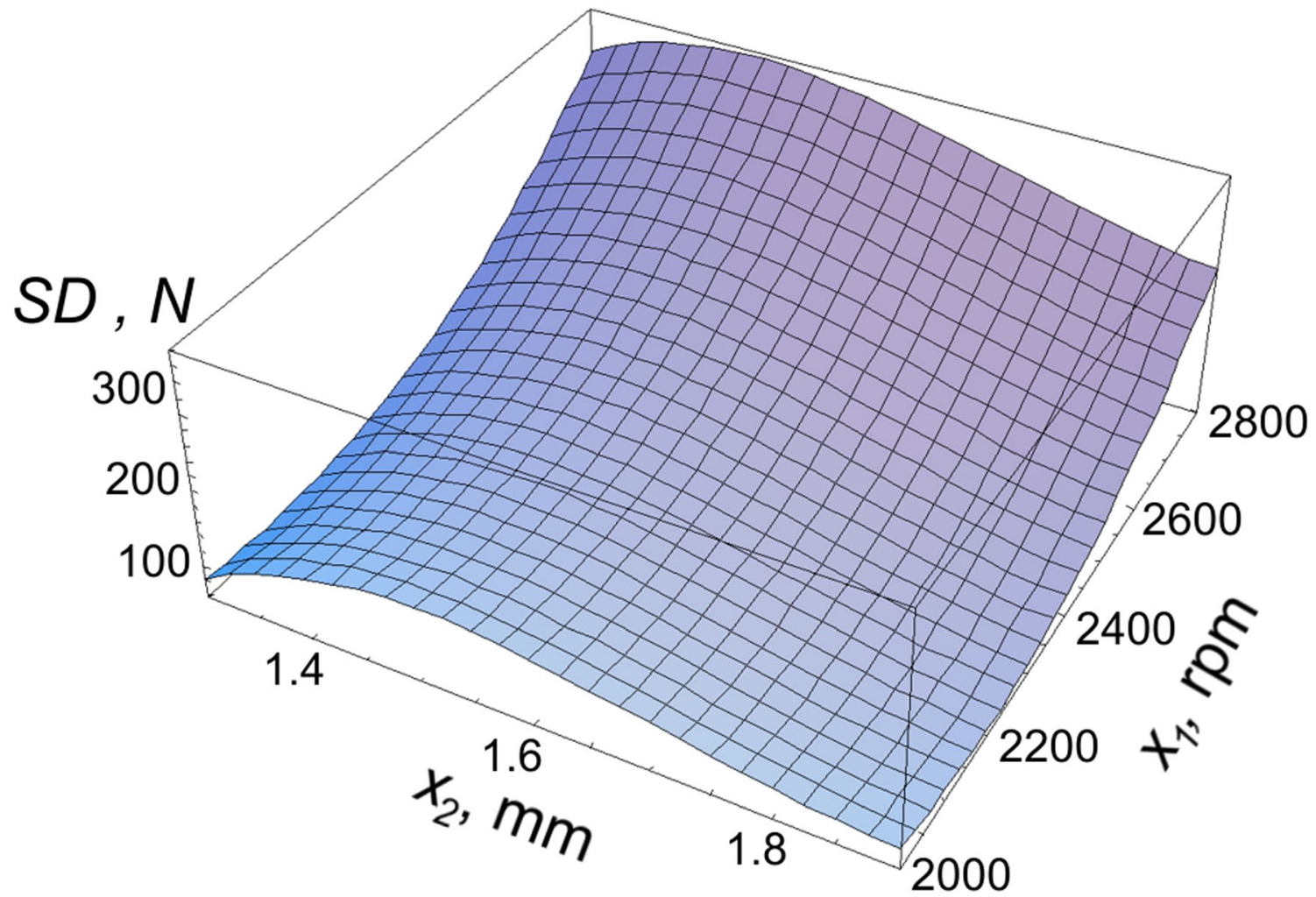

Fig. 11 The effect of tool rotational speed and tool plunge depth on the standard deviation of the load capacity of joint

- $\quad D \subset R^{m}$, a set of permissible solutions (a range of process setting parameters);

- $z=\left(z_{1}, z_{2}, \ldots, z_{m}\right) \in D$, acceptable solution;

- $f_{i}: D \rightarrow R, i$-th objective function $(i=1,2, \ldots, k)$;

- $\quad(z)=\left(f_{1}(z), f_{2}(z)\right.$, the objective function for a multi-criteria problem.

The problem of multi-criteria optimisation of the selection of process parameters can be written in the form of:

$\left\{\begin{array}{c}f_{1}(z)=W_{F}(x) \rightarrow \max , \\ f_{2}(x)=W_{\sigma}(x) \rightarrow \min , \\ z \in D\end{array}\right.$

The one-criteria problem:

$f_{i}(z) \rightarrow$ ekstremum, $\mathrm{z}, \in D$

is an $i$-th partial problem, where the vector $z^{i o} \in D$ in which the $i$-th objective function reaches the extremum searched. The vector:

$\varphi^{\circ}=\left(f_{1}\left(z^{l^{\circ}}\right), f_{2}\left(z^{2^{\circ}}\right)\right)$

is a vector called the ideal (utopian) solution in the space of evaluations, while: $z^{\circ}=\left(z^{1^{\circ}}, z^{2^{\circ}}\right)$

is the ideal solution for the function (8). Usually the ideal solution of function (8) is not available, which means that in the set of permissible solutions $D$ there is no vector $z^{o}$, for which all objective functions reach the extremum searched. Therefore, effective solutions were searched for during the solution of the problem presented.

The set of effective solutions usually contains many solutions. Therefore, the goal of the problem presented was to select one compromise (optimal) solution from a set of effective solutions. For this purpose, function (8) has been reduced to a single-criterion form, with the scalarisation function $s$ : $R^{k} \rightarrow R$ in the form:

$\max \left(s\left(f_{l}(z), f_{2}(z)\right): z \in D\right)$

Scalarisation of the function was carried out using the method of weighting the grades. Values of weights $u_{i}>0$ of particular criteria $f_{i}$ (fulfilling the condition $u_{1}+u_{2}=1$ ) were assumed, and then the optimal solution of the problem was determined (13):

$\max \left(\sum_{i=1}^{k} u_{i} f_{i}(z): z \in D\right)$ 


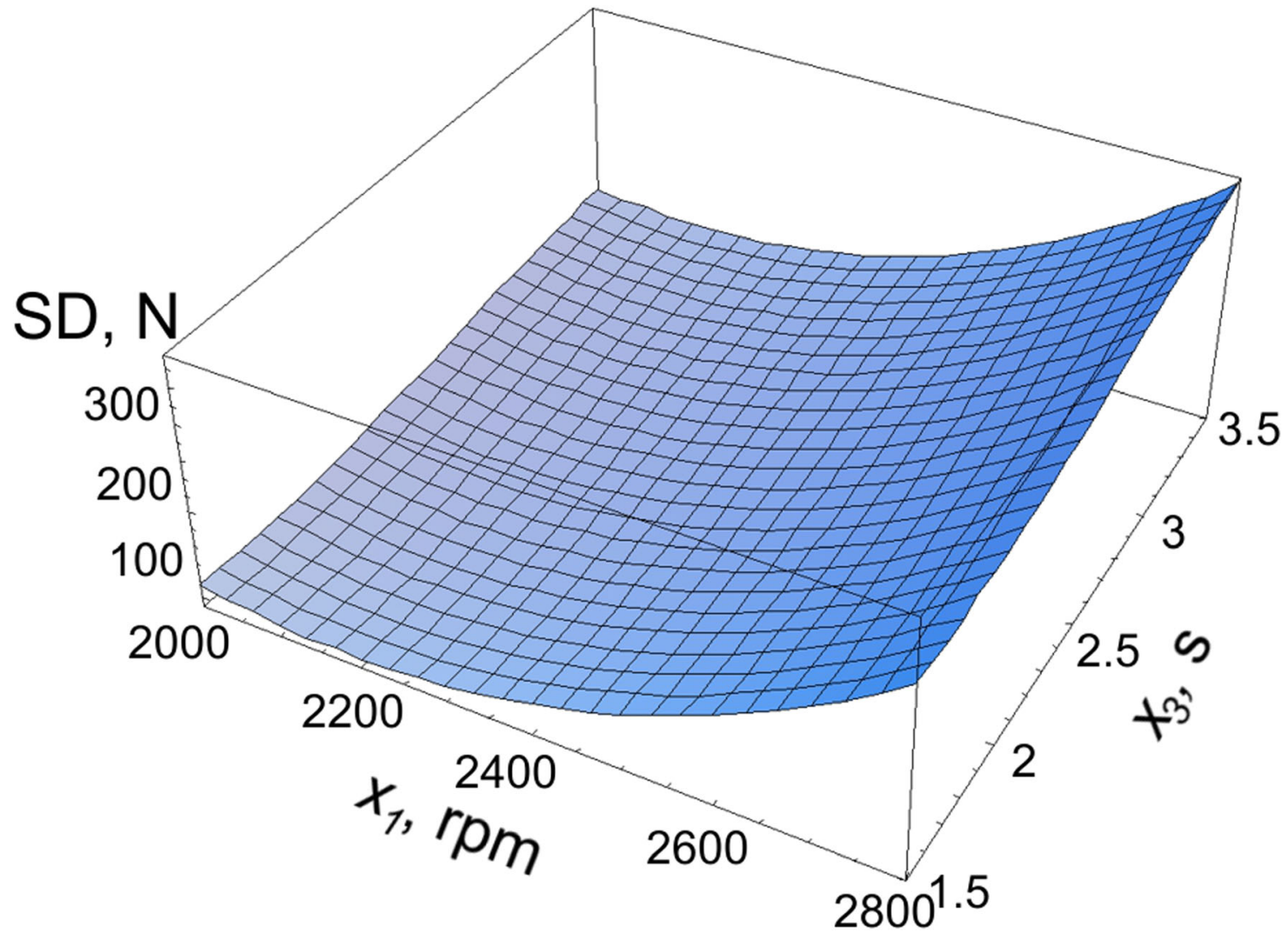

Fig. 12 The influence of tool rotational speed and duration of welding on the standard deviation of the load capacity of joints

It is only possible to create a function $\varphi(z)=\sum_{i=1}^{k} u_{i} f_{i}(z)$ if all the values of objective functions are expressed in the same units and scales. Since the objective functions in this case were expressed in different scales of values, they were transformed into a dimensionless form:

$f_{i}^{u}(z)=\frac{f_{k}(z)-\min \left(f_{k}(x): x \in D\right)}{\max \left(f_{k}(x): x \in D\right)-\min \left(f_{k}(x): x \in D\right)}$

Objective functions $f_{i}^{u}$ take values for $z \in D$ from the interval $[0,1]$ and they are dimensionless. The function describing the load capacity of the joint $W_{F}(x)$ reaches the maximum value of $7801.3 \mathrm{~N}$ at a speed $x_{1}=2800 \mathrm{rpm}$, tool plunge depth $x_{2}=$ $1.55 \mathrm{~mm}$, and duration of welding $x_{3}=1.5 \mathrm{~s}$, and minimum value of $5613.5 \mathrm{~N}$ at $x_{1}=2000 \mathrm{rpm}, x_{2}=1.9 \mathrm{~mm}$, and $x_{3}=1.5 \mathrm{~s}$. The maximum and minimum values obtained correspond to the extreme setting of parameters of the welding process at which the tests were carried out.

After transformation, the function describing the load capacity of the joint, which is a partial problem of the function (8), takes the following form:

$f_{1}^{u}(z)=\frac{W_{F}(x)-7801.3}{7801.3-5613.6}$
The second function describing the standard deviation of the dispersion of results takes the highest value $(380.87 \mathrm{~N})$ at a tool rotational speed $x_{1}=2800 \mathrm{rpm}$, tool plunge depth $x_{2}=$ $1.46 \mathrm{~mm}$, and duration of welding $x_{3}=3.5 \mathrm{~s}$, while the minimum value $(16.85 \mathrm{~N})$ is at $x_{1}=2226.55 \mathrm{rpm}, x_{2}=1.9 \mathrm{~mm}$, and $x_{3}=1.81 \mathrm{~s}$. Because both functions are to be maximised in the method of weighting the grades, the second function will take the form:

$f_{2}^{u}(z)=\frac{W_{\sigma}(x)-380.87}{380.87-16.85}$

After the unitarisation, an optimal solution of the problem is determined according to:

$\max \left(\sum_{i=1}^{k} u_{i} f_{i}^{u}(z): z \in D\right)$

The optimal solution of the function (17) is an effective solution to the multi-criteria problem. The form of the solution depends on the weight values $u_{i}$ adopted. If during the calculations, it is assumed that the load capacity of the joint is the most important parameter determining the quality of the joint $\left(u_{1}=1, u_{2}=0\right)$, then the solution obtained coincides with the optimal solution of the partial problem (Eq. 15) (point P1 in Fig. 13). 
Fig. 13 Results of the solution of the multi-criteria optimisation problem

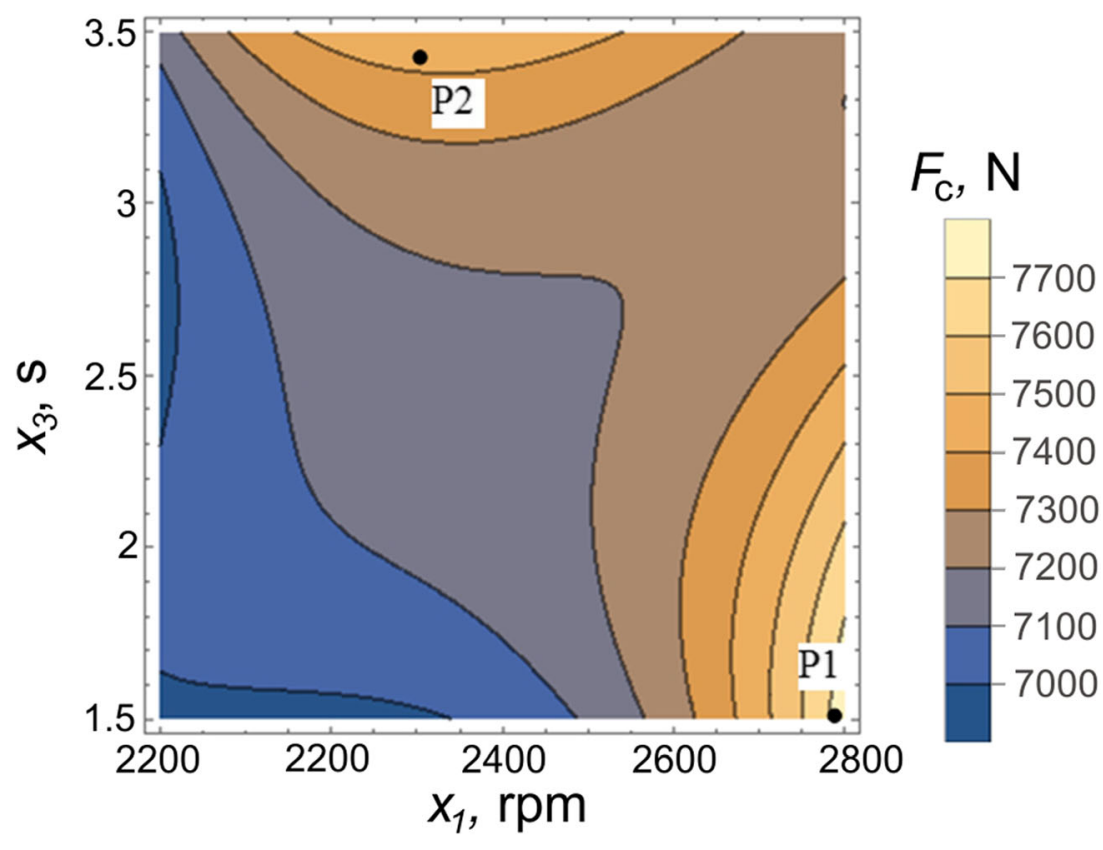

In the case of adopting equal values of the weights $(u$ ${ }_{i}=0.5$ ), the function (17) achieves the maximum for a tool rotational speed $x_{1}=2229 \mathrm{rpm}$, tool plunge depth $x_{2}=$ $1.60 \mathrm{~mm}$, and duration of welding $x_{3}=2.02 \mathrm{~s}$. This corresponds to the load capacity of the joint equalling 7071.5 $\mathrm{N}$ and a standard deviation of the dispersion of results of $86.22 \mathrm{~N}$. If, on the other hand, different weight values are adopted during the optimisation process, then another compromise solution can be obtained. Assuming that the load capacity of the joint is more important than the process variance $\left(u_{1}=0.6, u_{2}=0.4\right)$, the optimal solution moves to the point corresponding to the rotational speed $x_{1}=2256.05 \mathrm{rpm}$, tool plunge depth $x_{2}=1.55 \mathrm{~mm}$, and duration of welding $x_{3}=3.4 \mathrm{~s}$ (point P2 in Fig. 13). The application of the given process for setting parameters provides the opportunity to obtain a joint load capacity of $7462.37 \mathrm{~N}$ with a standard deviation of the dispersion of results of $142.09 \mathrm{~N}$. In order to verify the results obtained, 6 welds were made with parameters corresponding to the point $\mathrm{P} 2$ in Fig. 13, and then tensile/ shear tests were performed. The average value of the load capacity of the joint was $7511 \mathrm{~N}$, which is $0.6 \%$ more than the value obtained as a result of optimisation with a standard deviation of $102.3 \mathrm{~N}$.

Welds fabricated with optimal parameters were characterised by a lack of visible incomplete refill between the weld side and the upper sheet, a lack of voids on the outer edge of the weld and the lack of a clear structural notch (Fig. 14). The Alclad swirl existing in the bottom part of the weld results from insufficient stirring of the Alclad with the base materials. It is a basic defect of joining clad coated sheets [12, 13, 21, 23]. The cross section of the RFSSW joint thus formed reveals four regions in terms of the microstructural characteristics of
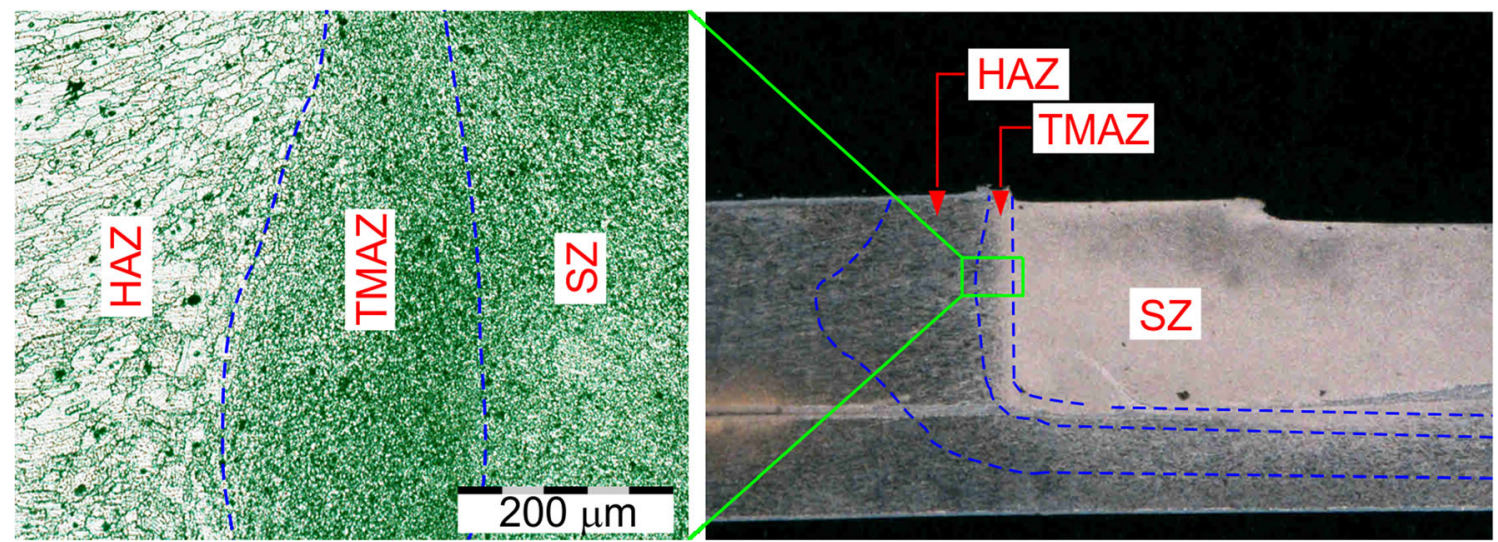

Fig. 14 Weld made with the optimal parameters of the RFSSW process 
the joint in the sequence from the SZ towards the BM (see example in Fig. 14). The visible HAZ has a small width and depth. This is due to the presence of the Alclad, which has a higher thermal conductivity $(229 \mathrm{~W} / \mathrm{mK})$ than the BM $(134 \mathrm{~W} / \mathrm{mK})$ and very rapidly transfers the heat out of the joint.

\section{Summary and conclusions}

In this paper, a method of optimisation of the RFSSW process parameters, i.e. rotational speed, tool plunge depth, and welding time, was presented that assures the maximum load capacity of the RFSSW joint. The main conclusions drawn are as follows:

1. Tool rotational speed has the greatest impact on the load capacity of RFSSW joints. An increase in this parameter permits the required temperature and pressure ensuring adequate plasticisation of the base material and the recrystallisation process to be obtained, thus ensuring the proper microstructure of the joint.

2. However, high rotational speed ensured that the appropriate load capacity of the joints also adversely affects the weld structure. Defects appear in a weld fabricated at too high a tool rotational speed, and the weld face is often very uneven, which makes it difficult to obtain the required tool plunge depth, significantly affecting the load capacity of the joints. As a result, the welding process is burdened with a high variance among the results obtained.

3. The results of the optimisation conducted showed that significantly better weld properties can be obtained by increasing the duration of welding. The joints obtained in this way have a smaller number of defects. Furthermore, the temperature resulting from the welding process, which interacts over a longer period of time, allows the material to be recrystallised and the removal of any structural notches caused by the penetration of the tool sleeve. From this point of view, this parameter, despite having a smaller impact on the load capacity of the joints, is more advantageous for process control. It provides joints with the load capacity required and at the same time with a small variance of their dispersion.

4. It should also be noted that the increases in the load capacity of the weld obtained by extending the duration of welding time are limited. If the welding time is too long, this leads to unfavourable phenomena in the HAZ manifested by a sharp reduction in the load capacity of joints.

5. The choice of the RFSSW process parameters therefore requires compromise solutions, i.e. the selection of tool rotational speed at a level ensuring adequate plasticisation of the base material and to obtain the required load capacity of the joint and then a welding duration ensuring that the appropriate joint microstructure is obtained, thus conditioning the required process repeatability.

RFSSW is one of the most modern methods of joining aluminium alloys. The research conducted has shown that this method can be successfully used in the aircraft industry, due to the possibility of ensuring high strength joints while reducing the labour consumption in the process of the assembly of welded structures.

Acknowledgements The authors of this paper would like to kindly thank Dr. Wojciech Bochnowski from the University of Rzeszow for the preparation of the SEM micrographs.

Open Access This article is distributed under the terms of the Creative Commons Attribution 4.0 International License (http:// creativecommons.org/licenses/by/4.0/), which permits unrestricted use, distribution, and reproduction in any medium, provided you give appropriate credit to the original author(s) and the source, provide a link to the Creative Commons license, and indicate if changes were made.

\section{References}

1. Zhang Z, Yang X, Zhang J, Zhou G, Xu X, Zou B (2011) Effect of welding parameters on microstructure and mechanical properties of friction stir spot welded 5052 aluminum alloy. Mater Des 32:44614470. https://doi.org/10.1016/j.matdes.2011.03.058

2. Yang XW, Fu T, Li WY (2014) Friction stir spot welding: a review on joint macro- and microstructure, property, and process modelling. Adv Mater Sci Eng 2014:697170. https://doi.org/10.1155/ 2014/697170

3. Lacki P, Derlatka A (2015) The plastic deformation of RFSSW joints during tensile tests. Arch Metall Mater 60:2585-2591. https://doi.org/10.1515/amm-2015-0418

4. Saha KS (2017) Aerospace manufacturing processes. CRC Press, Suite

5. Rajan R, Kah P, Mvola B, Martikainen J (2016) Trends in aluminium alloy development and their joining methods. Rev Adv Mater Sci 44:383-397

6. Mathers G (2002) The welding of aluminium and its alloys. Woodhead Publishing Ltd., Cambridge

7. Li Z, Hao C, Zhang J, Zhang H (2007) Effects of sheet surface conditions on electrode life in resistance welding aluminum. Weld J 88:81-89

8. Yan DY, Aiping W, Silvanus J, Shi QY (2011) Predicting residual distortion of aluminum alloy stiffened sheet after friction stir welding by numerical simulation. Mater Des 32:2284-2291. https://doi.org/10.1016/j.matdes.2010.11.032

9. Nikoleris T, Gupta G, Kistler M (2011) Detailed estimation of fuel consumption and emissions during aircraft taxi operations at Dallas/ Fort Worth International Airport. Transport Res D: Tr E 16:302308. https://doi.org/10.1016/j.trd.2011.01.007

10. Cao JY, Wang M, Kong L, Zhao HX, Chai P (2017) Microstructure, texture and mechanical properties during refill friction stir spot welding of 6061-T6 alloy. Mater Charact 128:54-62. https://doi. org/10.1016/j.matchar.2017.03.023

11. Chen Y (2015) Refill friction stir spot welding of dissimilar alloys. $\mathrm{PhD}$ thesis. University of Waterloo, Waterloo

12. Kubit A, Bucior M, Wydrzyński D, Trzepieciński T, Pytel M (2018) Failure mechanisms of refill friction stir spot welded 7075-T6 
aluminium alloy single-lap joints. Int J Adv Manuf Technol 94: 4479-4491. https://doi.org/10.1007/s00170-017-1176-2

13. Shen Z, Chen Y, Hou JSC, Yang X, Gerlich AP (2015) Influence of processing parameters on microstructure and mechanical performance of refill friction stir spot welded 7075-T6 aluminium alloy. Sci Technol Weld Join 20:48-57. https://doi.org/10.1179/ 1362171814Y.0000000253

14. Shen Z, Yang X, Zhang Z, Cui L, Li T (2013) Microstructure and failure mechanisms of refill friction stir spot welded 7075-T6 aluminum alloy joints. Mater Des 44:476-486. https://doi.org/10. 1016/j.matdes.2012.08.026

15. Oberembt C, Allen C, Arbegast W, Patnaik A (2007) Screening for process variable sensitivity in refill friction spot welding of 6061 aluminium sheet. In: Mishra RS, Mahoney MW, Lienert TJ, Jata KV (eds) Friction stir welding and processing IV, the minerals, metals and materials society, Pittsburgh, pp 359-368

16. Tier MD, Rosendo TS, dos Santos JF, Huber N, Mazzaferro JA, Mazzaferro CP, Strohaecker TR (2013) The influence of refill FSSW parameters on the microstructure and shear strength of 5042 aluminium welds. J Mater Process Technol 213:997-1005. https://doi.org/10.1016/j.jmatprotec.2012.12.009

17. Verastegui RN, Mazzaferro JAE, Mazzaferro CCP, Strohaecker TR, dos Santos JF (2015) Welding of aluminum to DP600 steel plates by refill friction stir spot welding process (refill FSSW): preliminary results. Adv Mater Res 1082:123-132 https://doi.org/10.4028/ www.scientific.net/AMR.1082.123

18. Montag T, Wulfsberg JP, Hameister H, Marschner R (2014) Influence of tool wear on quality criteria for refill friction stir spot welding (RFSSW) process. Procedia CIRP 24:108-113. https://doi. org/10.1016/j.procir.2014.08.015
19. Tutar M, Aydin H, Yuce C, Yavuz N, Bayram A (2014) The optimisation of process parameters for friction stir spot-welded AA3003-H12 aluminium alloy using a Taguchi orthogonal array. Mater Des 63:789-797. https://doi.org/10.1016/j.matdes.2014.07. 003

20. Buffa G, Fratini L, Piacentini M (2008) On the influence of tool path in friction stir spot welding of aluminum alloys. J Mater Process Tech 208:309-317. https://doi.org/10.1016/j.jmatprotec. 2008.01.001

21. Kubit A, Kluz R, Trzepieciński T, Wydrzyński D, Bochnowski W (2018) Analysis of the mechanical properties and of micrographs of refill friction stir spot welded 7075-T6 aluminium sheets. Arch Civ Mech Eng 18:235-244. https://doi.org/10.1016/j.acme.2017.07. 005

22. Kudła K, Wojsyk K, Adamus K (2013) The properties of spotwelded joints produced by the FSSW and RFSSW methods. Obróbka Plastyczna Metali 24:193-203

23. Yang HG, Yang HJ (2013) Experimental investigation on refill friction stir spot welding process of aluminum alloys. Appl Mech Mater 345:243-246. https://doi.org/10.4028/www.scientific.net/ AMM.345.243

Publisher's note Springer Nature remains neutral with regard to jurisdictional claims in published maps and institutional affiliations. 